\title{
The Realistic Dilemma and Breakthrough Ways of Improving the Quality of Online Teaching Resources of Physical Education in Colleges and Universities
}

\author{
Huaijin Liu, Yuqi Liu, Junhao Feng \\ Faculty of P.E., Hunan Institute of Science and Technology, Yueyang, China \\ Email: tyxlhj@126.com
}

How to cite this paper: Liu, H. J., Liu, Y. Q., \& Feng, J. H. (2021). The Realistic Dilemma and Breakthrough Ways of Improving the Quality of Online Teaching Resources of Physical Education in Colleges and Universities. Advances in Physical Education, 11, 1-11.

https://doi.org/10.4236/ape.2021.111001

Received: December 3, 2020

Accepted: December 27, 2020

Published: December 30, 2020

Copyright $\odot 2021$ by author(s) and Scientific Research Publishing Inc. This work is licensed under the Creative Commons Attribution International License (CC BY 4.0).

http://creativecommons.org/licenses/by/4.0/

\begin{abstract}
With the rapid development of information technology, the Ministry of education has put forward new requirements for the quality of online teaching resources. In addition, the improvement of the quality of online teaching resources will directly affect the improvement of course teaching quality, which directly leads to the continuous improvement of the requirements of online teaching resources quality in Colleges and universities. This paper mainly analyses several modes of online teaching of physical education course in Colleges and universities, expounds the realistic dilemma of improving the quality of online teaching resources of physical education courses in Colleges and universities, and puts forward substantive suggestions for the high-quality development of online teaching resources of physical education courses in Colleges and universities, so as to find a breakthrough path and promote the quality of online teaching resources of physical education courses in Colleges and universities, so as to promote our country The development of online teaching resources of physical education.
\end{abstract}

\section{Keywords}

College Physical Education, Online Teaching Resources, Quality Improvement, Realistic Dilemma, Breakthrough Way

\section{The Background of the Development of Online Teaching Resources of Physical Education in Colleges and Universities}

\subsection{Policy Review}

In recent years, the number of large-scale open online courses and other forms 
of teaching is rising rapidly. In order to comply with the trend of the development of contemporary curriculum forms, but also for the opportunities and challenges brought by the development of information technology. The Ministry of Education of the People's Republic of China (2015) issued the opinions on strengthening the application and management of the construction of online open courses in Colleges and universities, and paid close attention to the development of online teaching quality of college physical education, and constantly promoted the combination of large-scale online open courses and the reform of Educational Technology teaching mode in Colleges and universities, held a positive attitude, and encouraged all kinds of colleges and universities to work together to build a China with China The online open course management system and course learning platform with cultural characteristics promote it to play a more active role in updating education concept, optimizing classroom teaching mode, improving teaching quality and promoting education system reform. With the rapid development of network digitization, the society has entered the era of information and artificial intelligence. Digital teaching resources are a new form of teaching resources under the background of informatization, and also one of the important contents of connotation construction of higher education (Yang \& Gu, 2011). As an important part of subject education in Colleges and universities, the construction of physical education teaching resources has made some achievements, but there are still some problems. The purpose of this paper is to explore the practical difficulties and breakthrough ways of high-quality development of physical education teaching resources in Colleges and universities, and to provide reference for the reform of physical education in China.

\subsection{Resource Form}

\subsubsection{Micro Lecture}

Nowadays, with the popularity of smart phones, Wechat has become a widely used application software of instant messaging service; Wechat can quickly send voice messages, videos and pictures, and support multi crowd chat and exchange, which is very beneficial for college students to carry out interactive learning, so it is welcomed by teachers and students, and has rapidly developed into an information platform widely used in education and teaching. Micro class came into being. It takes video as the main carrier to record teachers' wonderful teaching and learning activities around a certain knowledge point, especially the key, difficult and doubtful points, in the process of teaching and teaching inside and outside the classroom. In other college courses, the application of micro class is very common, but it is not common in physical education. The application of micro class in other disciplines not only improves the interest of the classroom, but also enhances the enthusiasm of college students. Similarly, if micro class is applied to physical education, it can also play the same role, and it is more in line with the level of physical education classroom teaching.

From the point of view of the task of physical education course, it gives students more sufficient practice time. The main task of physical education curri- 
culum is to teach students the most basic knowledge of physical education and sports movements through the organization and demonstration of physical education teachers, so as to promote the overall development of students' bodies and minds. In the traditional physical education teaching process, for a certain sports technical action, physical education teachers should carry out multiple decomposition demonstration and teaching, so that students can better understand learning, and this will often lead to a large loss of classroom time in the teacher's multiple explanations and demonstrations, and students' own practice time will be correspondingly reduced. The emergence of PE micro class can let the teacher send the PE learning content of this class to the corresponding students through the network PE platform before class, so that the students can preview the PE technical action required by this class before class, and have a corresponding understanding of the sports action to be learned. In the classroom, teachers can also spot check the actions that students learn before class, point out the wrong actions directly, reduce the redundant actions, hit the key points directly, and leave students as much practice time as possible, so as to effectively improve the teaching quality (Lu \& Yang, 2020).

From the development of sports micro class itself, it is a kind of online teaching mode based on micro video teaching, which is designed and developed for the technical action or Tactical Teaching of sports teaching, and supports the coexistence of multiple learning methods. It greatly meets the learning habits of contemporary college students who like fragmented learning, so that college students as long as they have free time. Time can be anytime and anywhere to learn new sports movements and sports movements that are not fully mastered, greatly improving the convenience of contemporary college students to learn sports movements. Moreover, it also provides great convenience for college students to review sports movements and solves the dilemma of College Students' sports movements that they do not understand, and it is difficult to find teachers to learn.

\subsubsection{MOOC}

MOOC is a large-scale online course in the new era, which is the product of the progress of the times. Massive open online courses. It is a new online course development model. The emergence of MOOC has brought new vitality to the theoretical teaching of physical education in Colleges and universities. Physical education theory course is the teaching of scientific theoretical knowledge, which is different from pure skill teaching, so it has common characteristics with other courses in the classroom. Affected by the epidemic situation, the teaching of colleges and universities across the country is facing unprecedented challenges. With the normalization of the epidemic situation, the Ministry of education has issued a number of documents, such as "no suspension of classes", "no return to school" and so on. In response to the call, colleges and universities have carried out online teaching. Physical education is a course based on body exercises, which enables students to master certain sports skills, and the physical 
education of students at home How to carry out education and teaching, combined with the teaching experience of various disciplines, MOOC teaching platform in Chinese universities has become the best choice of college physical education teaching. The original intention and application concept of MOOC is also applicable to the teaching of physical education theory courses in Colleges and universities. The application of MOOC platform can learn from and use the resources of high-quality sports and health courses at home and abroad, and absorb advanced teaching methods And teaching means, so that sports theory teaching form more colorful, to improve the desire for knowledge of college students, self-study, master the method of scientific fitness, as well as to improve the quality of sports theory teaching. At present, MOOC of sports theory has been recognized in Colleges and universities, and gradually popularized and applied.

\subsubsection{Excellent Online Courses}

With the Ministry of education's construction of network excellent course documents, we realize that the network education excellent course has four first-class courses, which include first-class teacher team, first-class class content, first-class teaching methods and teaching materials, as well as first-class teaching management. At the same time, it is also a high generalization of the content depth of network excellent courses. What is "first class"? What is "demonstration"? What is the difference between the requirements of undergraduate and tertiary quality courses and ordinary universities? In addition, people have different understanding of "course" and "excellent course", so far there is no consensus on the concept of network education quality course. In my opinion, the essence of network education courses can be recognized and positioned from the following three different aspects.

From the nature of the network excellent course, the excellent course of network education should focus on cultivating all-round talents, correctly handle the relationship between the practicality of teaching content and the systematisms of knowledge system, and correctly handle the relationship between the combination of theoretical basic knowledge, subject frontier knowledge and practical application knowledge, Deeply explore the characteristics of network excellent courses.

From the characteristics of university courses to understand the network quality courses. According to the characteristics that students have enough spare time and like fragmented learning, network excellent courses make full use of this feature to promote students' active learning, which not only improves the teaching quality, but also makes college students' enthusiasm for fragmented learning higher.

From the evaluation index of network excellent course, we can understand the network excellent course. There is a big difference in the evaluation index between the excellent course of network education and the excellent course of undergraduate and junior college. Network quality courses should not only imple- 
ment the national quality course construction standards, but also pay special attention to "learning resources", "teaching process" and "learning support services" and other evaluation indicators to adapt to the characteristics of network quality courses education.

For physical education courses in Colleges and universities, the emergence of network quality courses not only solves the problem of time and space constraints of offline physical education courses, but also improves the problems of single teaching content and low teaching quality of physical education courses, and makes college students' enthusiasm for physical education courses rise. In addition, students can also use sports network excellent courses for action learning in their spare time, greatly improve the learning efficiency.

\subsubsection{Video Open Class}

Video open class is introduced into China in recent years. It generally refers to the teaching and academic videos, audio-visual materials, etc., which are mainly for college students and open to the public free of charge with the help of network platform. It is a special form of network education. Teachers teach and interact with teachers and students in real class. It is recorded in the form of video plus subtitles, and widely spread through the network to achieve sharing, and ultimately meet the learning needs of the public.

Sports video open class, through using of the image, sound effect, subtitles and editing effect, which can help improve the students on the visual and auditory impact, so that students can understanding of various sports movements intuitively. And can focus on the key and difficult points of sports movements, so that students can be more impressed with sports movements. The wide application of video teaching not only enriches the teaching content and teaching form, but also enhances the students' enthusiasm for the physical education class and stimulates the students' interest in sports.

\section{The Realistic Dilemma of Improving the Quality of Online Teaching Resources of Physical Education in Colleges and Universities}

\subsection{Lack of Long-Term Planning for Resource Construction}

There is a lack of long-term planning for the development of digital teaching environment resources of College Students' physical education, and the management mechanism of co construction and sharing is not perfect, showing the characteristics of decentralization. There is not only a clear guiding ideology and overall design planning, but also a lack of specialized internal management research institutions. These departments include academic affairs office, library, modern social education science and technology service center and physical education department. These departments do their own work, and do not gather together to communicate and coordinate, which not only increases the organization cost of operation, but also hinders the integration of digital teaching resources. 


\subsection{Lack of Continuous Maintenance of Resource Application}

Since the traditional classroom has gradually changed to digital classroom, all kinds of colleges and universities in China have begun a new round of classroom mode reform. In this wave of education reform, colleges and universities in China have accelerated the co construction and sharing of digital teaching resources. However, at present, many university management staff do not keep pace with the times, and even do not understand what the education mode under the concept of MOOC is, and seriously lack of attention to the development and application of digital technology teaching environment resources in Colleges and universities The investment in human, material and financial resources is far from enough, and the investment in physical education teachers is even less (Berlin, Cong, \& Yang, 2020). The serious backwardness of ideas and the small investment in physical education have a great impact on the process of high-quality development of sports digital teaching content resources.

\subsection{There is no Uniform Standard for Resource Evaluation}

At present, the digital teaching of physical education course in Colleges and universities lacks unified technical standards and curriculum standards. In particular, there is a serious lack of communication and communication between various colleges and universities, which directly leads to the lack of unified technical standards, unified resource classification rules and corresponding file formats in the construction of sports digital teaching resources, which makes it extremely difficult to search and use different platforms. In addition, most colleges and universities for the development of sports digital teaching resources are self-sufficient, and there is not much linkage with the same type of domestic colleges and universities, which directly leads to the joint development of sports digital teaching resources between colleges and universities is very few. In the developed digital teaching resources of physical education, because there is no investigation on the actual needs of different colleges and universities, and there is no unified standard of university sports digital resources, so the digital teaching resources have a single type, low-level repeated construction, and low degree of fit with teaching (Zhang, 2020).

\section{The Breakthrough Ways of Improving the Teaching Quality of Physical Education in Colleges and Universities}

\subsection{To Establish a Long-Term Mechanism for Inter School Collaboration and Sharing}

The unified management mechanism is the guarantee of the integration of university sports digital learning resources. According to the actual development of the students in each university, the physical education teachers in each university should establish a unified management and research institution under the guidance of digital teaching concept, strengthen the cooperation among departments in Colleges and universities, promote the communication among depart- 
ments in Colleges and universities, and make all departments work together to solve the problems of digital teaching in Colleges and universities, and avoid the waste of resources and time And the problem of low-level repeated construction. In addition, colleges and universities also need to build regulatory agencies to evaluate specific sports digital teaching resources, dynamic monitoring, tracking, evaluation and improvement of sports digital teaching resources sharing, so as to promote the goal of sports digital teaching resources sharing, standardize, and constantly improve the management efficiency.

The construction and development of digital teaching resources with different colleges and universities is its flash point. Like other disciplines and specialties, there are also differences between the levels of colleges and universities and regional differences. The proportion of curriculum development of national sports undergraduate is uneven, the distribution of different disciplines in different types of universities is also different, and the development of curriculum types in normal universities is relatively balanced. Sports colleges and universities have great advantages in sports training and sports humanities, which can promote the continuous cooperation and sharing between colleges and universities and avoid the waste of resources and funds.

\subsection{Investment in Human Capital and Continuous Updating of Human-Computer Interaction}

All university education management staff must update the old teaching management concept, at the same time to establish innovative consciousness, fully make teachers of all disciplines realize that information education is the inevitable trend of the development of higher education, and for physical education teachers, the concept of co construction and sharing of digital teaching environment resources is also the inevitable product of the continuous development of contemporary education concept (Liu, Nie, \& Wu, 2015). Therefore, colleges and universities should incorporate the co construction and sharing of digital teaching resources into the education and teaching reform and development plan, constantly speed up the process of school management informatization, and increase the input of human, financial and material resources, so as to combine the digital teaching resources of physical education with the characteristics of Colleges and universities to improve the level of modern education information management (Lu, 2020).

\subsection{Form the Evaluation Standard, Eliminate the Fittest and Create the Gold Class}

\subsubsection{Build the Whole Process Evaluation Index System, Closely Combine the Process Evaluation and the Result Evaluation}

Wu Yan, director of the Department of higher education of the Ministry of education, delivered a report entitled "building China's golden course" at the $11^{\text {th }}$ "China University Teaching Forum" on November 24, 2018. This paper puts forward the gold curriculum standard which embodies innovation, difficulty, 
and challenge, and advocates the teachers to deeply discuss the specific requirements and implementation path of building China's golden course ( $\mathrm{Wu}, 2018)$. It emphasizes that the content of the course should keep pace with the times and be forward-looking; it should enrich the teaching forms with information technology, strengthen the interaction between teachers and students and students, take students as the main body, and teachers lead to form inquiry and personalized learning; cultivate students' ability of systematic thinking and problem-solving, and realize the organic integration of theory and skills (Huang, 2020); the curriculum should be challenging and need to make efforts There should be higher requirements for teachers' teaching preparation and students' task arrangement after class. Therefore, the orientation of "golden class" classroom is oriented by developmental evaluation and benchmarked by "golden class" standard. Under the guidance of the "golden class" evaluation concept, college physical education curriculum should set up the training goal of high-quality applied talents of physical education specialty with theory in place and practical skills. The basic characteristics of application should be highlighted in physical education classroom teaching. Referring to Bloom's classification theory of teaching objectives, this paper analyzes and expounds the three major fields of educational objectives: cognitive field, emotional field and action skill field, and The cognitive law of human learning process put forward by constructivism theory advocates the teaching methods of PE Teachers' leading and students' main body as the design principle and theoretical basis of index system.

\subsubsection{Focus on Curriculum Design, Clarify the Weight of Each Index, and Strive to Improve the Quality of Learning and Teaching}

With regard to the construction of national golden course, Wu Yan, director general of the Department of higher education of the Ministry of education, has put forward the official standard of "one degree for both sexes" which is high-level, innovative and challenging. The construction of mixed golden course of physical education curriculum in Colleges and universities should also be carried out around this standard, so as to improve the degree of curriculum challenge, expand the depth and breadth of knowledge, and increase the gold content of curriculum. Through the mixed teaching, we can stimulate students' learning interest and potential, let them increase their scientific burden, increase their learning input and get busy, so as to realize the learning challenge of "jump to get", and improve the quality of education and teaching. After research, the construction of "online and offline" hybrid golden course of physical education course in Colleges and universities emphasizes the discipline characteristics of practical exercise and personal experience and selects appropriate content for online teaching (Diao \& Wei, 2020). From the perspective of whether students' knowledge and skills acquisition method is based on Teachers' teaching or students' own practice, the teaching content of college physical education is summarized and divided into practical content( There are three main types: Students' own practice, theoretical content (teacher's teaching) and comprehensive 
content. The practical content mainly includes sports special skills learning and physical fitness practice, which mainly depends on the students' repeated practice with the help of teachers; the theoretical content mainly includes sports culture, sports theory (such as the birth, development and evolution of sports events, competition forms, etc.), sports etiquette, competition rules, etc., which are mainly discussed by teachers The comprehensive contents include scientific fitness method, exercise prescription, exercise recovery and so on.

\subsubsection{Increase the Evaluation Index in the Process of Teaching Design and Give Full Play to the Guiding and Guiding Role of the Index System}

Teaching process is the premise to ensure the quality of teaching. The most popular quality assurance framework focuses on online course design rather than online teaching. The evaluation index of our country highlights the online teaching and pays less attention to the curriculum design. Almost all the operators of digital teaching resources of physical education courses in Colleges and universities in China are newly established Internet companies, lacking experience, and accumulation in this respect. Therefore, although the digital teaching resources are well organized, the teaching design quality of the courses is low. Therefore, we need to use a variety of frameworks to carry out more research to further improve the quality of online teaching resources. Although China's current evaluation indicators cover the relevant indicators before, during and after the construction, there are relatively few indicators in the construction, and the guiding role of curriculum builders is weak. China's evaluation index system can also be more refined, in order to promote the curriculum builders to pay attention to the refinement of curriculum design and lay the foundation for creating a real "golden course". Therefore, on the basis of retaining the "curriculum application effect and impact" index, the evaluation index system in China can add specific indicators in the process of curriculum design, so as to facilitate the curriculum team to have laws to abide by in the course construction, or can continuously improve and improve the course quality according to the evaluation results after the construction, and play the guiding and guiding role of evaluation indicators.

\section{Summary}

In order to improve the quality of online resources of physical education, it is necessary to strengthen the construction of sharing mechanism from the realistic dilemma of improving the quality of online resources of physical education teaching. In particular, various colleges and universities should make more exchanges and share teaching resources, timely understand the problems and difficulties encountered in improving the quality of online teaching resources in various colleges and universities, and make timely response to specific topics according to the needs In terms of investment, we should increase the investment in human and capital to improve the quality of online resources, so that 
the quality of online resources has always been at the forefront; in the aspect of curriculum evaluation, we should update the evaluation standards in time, build a whole process evaluation index system along with the latest evaluation standards, so as to realize the online quality and course teaching quality of physical education Double promotion, to achieve the high quality of physical education teaching online resource quality, for China's physical education to transport high-quality comprehensive talents, to make substantial contributions to China's physical education.

\section{Acknowledgements}

This study was sponsored by funds of the Hunan Provincial Social Sciences Achievement Review Committee "Problems and Countermeasures of online teaching resources in Colleges and Universities under the normalization of epidemic prevention and control" (XSP21ZDI006), "13th five year plan" of Hunan Education Science in 2020 "theoretical framework and practical path research on the construction of online" golden course "of physical education in Colleges and universities (XJK20BTW002), teaching reform research project of Hunan Institute of science and technology in 2020" exploration and practice of online and offline hybrid "golden course" construction of physical education in Colleges and universities (2020B05) and Nanhu College of Hunan Institute of science and technology in 2020 "research and practice of the construction of online open courses of physical education in Independent Colleges Based on 020".

\section{Conflicts of Interest}

The authors declare no conflicts of interest regarding the publication of this paper.

\section{References}

Berlin, Cong, P., \& Yang J. P. (2020). Research on the Auxiliary and Application of Digital Platform in College Physical Education. Journal of Jiamusi University (NATURAL SCIENCE Edition), 2, 133-135.

Diao, X. H., \& Wei, R. L. (2020). Exploration on the Construction Path of "Online and Offline" Hybrid Golden Course of Physical Education in Colleges and Universities. Journal of Zhejiang Ocean University (Humanities Edition), 3, 80-86.

Huang, J. (2020). Research on the Construction of Classroom Teaching Evaluation System in Applied Undergraduate Universities from the Perspective of "Golden Class". Science and Education Guide, 8, 15-16.

Liu, H. J., Nie, J. S., \& Wu, Y. X. (2015). Construction of Digital Teaching Resources in Colleges and Universities: Ideas, Strategies, and Paths-Based on the Perspective of Education Informatization. Modern Education Management, 9, 89-94.

Lu, B. (2020). Physical Education and Teaching under the Background of Digital Campus. Contemporary Sports Science and Technology, 4, 66-68.

Lu, P. T., \& Yang, Y. D. (2020). Application of Micro Class in College Physical Education Practice Teaching. Education and Teaching Forum, 41, 242-244.

The Ministry of Education of the People's Republic of China (2015). Opinions on Streng- 
thening the Application and Management of Online Open Courses in Colleges and Universities. http://www.gov.cn/xinwen/2015-04/28/content_2854089.htm

Wu, Y. (2018). Construction of "Golden Class" in China. Teaching in China University, $12,60-63$.

Yang, M. G., \& Gu, M. Y. (2011). Discussion on the Basic Concept of Excellent Course Construction of Online Education. China Distance Education, 11, 57-61.

Zhang, B. (2020). Construction of Digital Teaching Resources in Application-Oriented Universities-Taking Olympic College of Nanjing Institute of Physical Education as an Example. Education and Teaching Forum, 3, 299-301. 